WellBeing International

WBI Studies Repository

4-2012

\title{
The effect of neutering on the risk of urinary incontinence in bitches - a systematic review
}

\author{
W. Beauvais \\ Royal Veterinary College \\ J. M. Cardwell \\ Royal Veterinary College \\ D. C. Brodbelt \\ Royal Veterinary College
}

Follow this and additional works at: https://www.wellbeingintlstudiesrepository.org/endoc

Part of the Animal Studies Commons, Other Animal Sciences Commons, and the Other Veterinary Medicine Commons

\section{Recommended Citation}

Beauvais, W., Cardwell, J. M., \& Brodbelt, D. C. (2012). The effect of neutering on the risk of urinary incontinence in bitches-a systematic review. Journal of Small Animal Practice, 53(4), 198-204. DOI:

10.1111/j.1748-5827.2011.01176.x

This material is brought to you for free and open access by WellBeing International. It has been accepted for inclusion by an authorized administrator of the WBI Studies Repository. For more information, please contact wbisr-info@wellbeingintl.org.

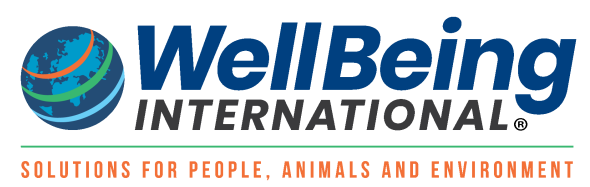




\title{
The effect of neutering on the risk of urinary incontinence in bitches - a systematic review
}

\author{
W. Beauvais, J. M. Cardwell and D. C. Brodbelt \\ Veterinary Epidemiology and Public Health Group, Royal Veterinary College, Hawkshead Lane, North Mymms, Hatfield, \\ Hertfordshire AL9 7TA
}

An increased risk of urinary incontinence in bitches has often been associated with previous ovariohysterectomy but remains controversial. The objective of this study was to evaluate the strength of evidence for an association between neutering or age at neutering and urinary incontinence in bitches and to estimate the magnitude of any effect found. A systematic review of peer-reviewed original English analytic journal articles was conducted, based on Cochrane guidelines (Higgins and Green 2009) Of 1,853 records screened, seven studies were identified that examined the effect of neutering or age at neutering on the risk of urinary incontinence but four were judged to be at high risk of bias. Of the remaining three studies, which were at moderate risk of bias, there was some weak evidence that neutering, particularly before the age of three months, increases the risk of urinary incontinence. However, overall the evidence is not consistent nor strong enough to make firm recommendations on the effect of neutering or age at neutering on the risk of urinary incontinence.

Journal of Small Animal Practice (2012) 53, 198-204

DOI: $10.1111 / \mathrm{j} .1748-5827.2011 .01176 . x$

Accepted: 30 November 2011; Published online: 21 February 2012

\section{INTRODUCTION}

This study was part of a larger project with the aim of assessing the risks and benefits of neutering bitches, at varying ages. The decision to neuter is complex and may have implications not only for the health of an individual bitch but also for her suitability as a pet or working dog, as well as wider effects on canine population dynamics because of a reduced number of strays or otherwise unwanted animals (Jagoe and Serpell 1988, Kustritz 2002, Howe 2006, Kustritz 2007).

An increased risk of urinary incontinence (due to sphincter mechanism incompetence, also known as hormonal urinary incontinence) in bitches has been attributed to spaying (ovariohysterectomy), particularly if performed before the first oestrous (Holt 1987, Holt and Thrusfield 1993). Proposed mechanisms of action include reduced levels of endogenous oestrogen, which may reduce tone in the uretheral sphincter, increased gonadotropin levels, decreased gonadotropin or cyclooxygenase-2 receptor expression, decreased amounts of smooth muscle in the urethra and bladder, changes to collagen structure and shorten- ing of the urethra (Gregory and others 1992, Byron and others 2007, Noël and others 2010).

In a recent survey of UK veterinarians, urinary incontinence was the second most commonly stated disadvantage of neutering bitches (Diesel and others 2010). While many affected bitches respond to oral therapy with synthetic oestrogens, this generally has to be continued for life (Shiel and others 2008). Furthermore, a recent study suggested that urinary incontinence in pet bitches was a cause of disharmony in 10 to $20 \%$ of affected households, with individual owners reporting feelings of anger and frustration (de Bleser and others 2011). Therefore, although the direct welfare impact may be considered minor for the affected animal, the potential impact on the owner-animal bond, coupled with the perceived importance of the condition in the neutering decision-making process, suggest systematic appraisal of the available evidence is merited.

The aims of this study were to evaluate the strength of evidence for an association between neutering, or age at neutering, and urinary incontinence in bitches and to estimate the magnitude, and precision, of any effect found. 


\section{MATERIALS AND METHODS}

\section{Protocol}

A systematic review was conducted, using a predefined protocol based on Cochrane guidelines. Any changes to the protocol during the review process are indicated in the description below.

\section{Search strategy}

The following terms were used to search both PubMed (U.S National Library of Medicine 2011) and CAB direct (Cab Direct 2011) databases:

1. Dog OR dogs OR bitch* OR canis* OR canine* OR canid* OR “Dogs" [MAJR]

2. SMI OR (sphincter AND mechanism AND incompetence) OR incontinent* OR [(urine OR urinary) AND leak*]

\section{(\#1 AND \#2)}

\section{[Medical Subject Headings (MeSH) terms in PubMed only]}

The search was conducted on December 8, 2010. No limits were set.

In addition, as part of a previous study (Beauvais and others submitted for publication), three databases (PubMed, ISI Web of Knowledge 2011 and CAB direct) had already been searched using the following terms:

1. Dog OR dogs OR bitch* OR canis* OR canine* OR canid* OR "Dogs" [MAJR]

2. Spey* OR Spay* OR neuter* OR ovariohysterectom* OR ovariectom* OR gonadect* OR gonad OR gonads OR "Ovariectomy/veterinary"[MAJR]

(\#1 AND \#2)

\section{(MeSH terms in PubMed only)}

This search was conducted on November 5, 2010. No limits were set. These results had already been screened according to criteria described below.

\section{Screening process}

All references were imported into Endnote (Thomson Reuters). Automatic deletion of duplicates was based on matching title, author and reference type. The remaining references were screened by the primary author to eliminate any that were clearly ineligible according to prespecified criteria (Table 1). Only peerreviewed original journal articles containing data concerning the association between neutering and urinary incontinence, or age of neutering and urinary incontinence, were included. Full text was retrieved for the remaining papers, which were also screened by the primary author to eliminate any that did not fit the eligibility criteria.

\section{Data extraction and assessment of bias}

The remaining papers were reviewed by two of the three authors. The data extraction form developed for a previous study (Beauvais and others) and based on Cochrane guidelines was adapted for this purpose. Questions on bias were based on Cochrane (trials)

\section{Table 1. Eligibility criteria for inclusion in the systematic}

\section{review}

Eligibility criteria

1. EITHER the presence/absence of urinary incontinence has been classified in both neutered and entire female dogs (or animals neutered at different ages)

OR the frequency of neutering (or neutering at different ages) has been measured in both female dogs with and without a history of urinary incontinence

2. The measurements given in criterion 1 , or the results of analysing these measurements, have been stated in the report

3. The "neutered" dogs were neutered by ovariectomy or ovariohysterectomy"

4. The report was an original research paper ${ }^{\dagger}$

5. The report was published in a peer-reviewed section of a journal (according to details on the journal's website) ${ }^{\dagger}$

6. The full text of the report was available in English ${ }^{\dagger}$

"Where the definition of neutering was not stated, it was assumed that it was by ovariohysterectomy or ovariectomy

tThese criteria were added in the course of the review process because of practical constraints

(Higgins and Green 2009), Newcastle Ottawa (cohort, case control studies) (Ottawa Hospital Research Institute 2011) and Downs and Black (cross-sectional studies) (Downs and Black 1998) tools. Question formats were altered so that the reviewer was asked first to describe a feature of the study and then to answer a question to which the answers yes, no or unclear denoted high, low or unclear risk of bias, respectively. The risk of bias for each study question (i.e. effect of neutering and effect of age at neutering) was classified according to the SIGN (Scottish Intercollegiate Guidelines Network) "levels of evidence" system, which was modified to include cross-sectional studies as has been done previously (University of Liverpool 2011). In addition, an intermediate category ("2") was defined to accommodate studies with a "moderate risk of confounding or bias" (Scottish Intercollegiate Guidelines Network 2008).

Extracted data were entered into a Microsoft Excel spreadsheet. Disagreement between reviewers was resolved by consensus. Where further information was required, authors of the original report were contacted.

\section{Data analysis}

Studies were grouped according to whether they investigated the effect of neutering or age at neutering. As there was clearly heterogeneity within each group, no statistical test for heterogeneity or quantitative meta-analyses were performed. Each of the three authors assessed the overall strength of evidence for each outcome using the SIGN system (Scottish Intercollegiate Guidelines Network 2008), which rates the strength of recommendations for clinical interventions from A (strongest) to D (weakest). Disagreements were again resolved by consensus. The preferred reporting items for systematic reviews and Meta-analyses statement was followed where possible (Liberati and others 2009).

\section{RESULTS}

The searches for reports containing terms relating to urinary incontinence retrieved 1271 references, as shown in Figure 1. In 
addition, 523 papers were screened from the results of a previous search that included terms relating to dogs and neutering. After duplicates were eliminated 1583 reports remained and following removal of those that clearly did not meet the eligibility criteria, 41 remained. Three of these references were eliminated as full-text articles could not be accessed via resources available at the British Library, Royal Veterinary College or freely online. However, it was strongly suspected from the references that none of these were peer-reviewed original research articles (O'Nualláin 1987, Phillips 1992, Galav and Singh 2004). Fifteen reports were eliminated because they did not address the research question (eligibility criterion 1) and 13 were not original research articles (criteria 4).

Of 10 studies that passed the screening so far, three were eliminated at the data extraction phase because it became clear that they did not, in fact, meet the eligibility criteria (Table 1). In two of the reports the measure of association between neutering and urinary incontinence in bitches was not presented and could not be calculated from the data presented (Howe and others 2001, Mandigers and others 2006). In the third, although it initially appeared that our research question was addressed, the controls had been selected almost exclusively from bitches presenting for ovariohysterectomy, thus precluding any analysis of the association between urinary incontinence and ovariohysterectomy. Of the seven papers that remained, four were judged to be at high risk of confounding or bias, according to the SIGN system, and were excluded on this basis. The three remaining papers were rated as SIGN Level 2 (case control, cohort and cross-sectional studies with a moderate risk of confounding or bias). Only these three papers

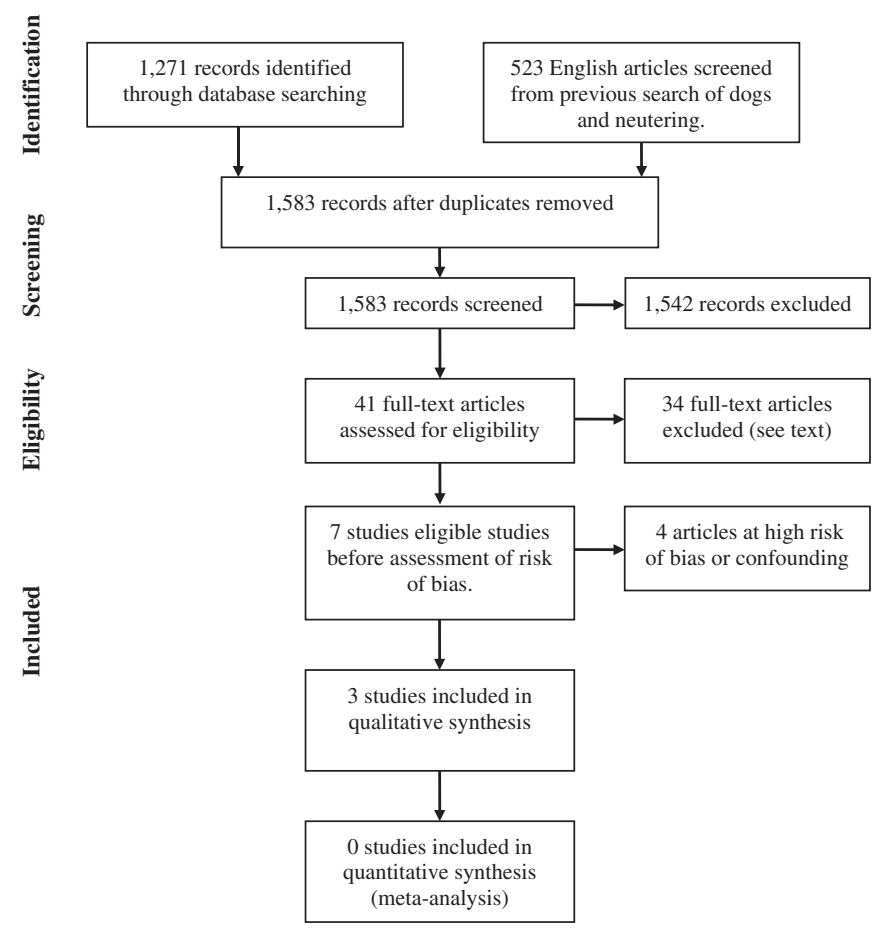

FIG 1. Flowchart (template provided by PRISMA) showing numbers of reports at each stage of the screening process were included in the final synthesis of results. Only one of these papers addressed the association between neutering and urinary incontinence (Thrusfield and others 1998), and all three addressed the association between age at neutering and urinary incontinence.

\section{Summary of studies excluded due to bias}

Table 2 shows the assessment of risk of bias for each of the four studies excluded due to bias, two of which were cohort studies and two cross-sectional studies. None of these controlled for the effect of breed or age or described clearly how incontinent and continent animals were classified. In particular, in one study (Holt and Thrusfield 1993) the term "hormonal incontinence," was used, which strongly implies that the bitch is spayed and would not normally be used to describe incontinence in entire bitches at all. This could lead to an over-estimate of the association between spaying and incontinence. In one study, (Stocklin-Gautschi and others 2001) the neutered and entire dogs were not selected from the same practices, leading to potential bias. In another study (Holt and Thrusfield 1993) it appeared that neutered and entire dogs could have differed with respect to whether they were pure- or cross-breeds, although this was unclear. There were other areas of uncertainty as shown in Table 2.

\section{Key features of included studies}

Two of the included studies were cohort studies (Table 3), one including dogs that were re-homed by a charity in the USA (Spain and others 2004) and the other including practice-attending dogs in the UK (Thrusfield and others 1998). The final included study was a case-control study, also of practice-attending dogs in the UK (de Bleser and others 2011).

\section{Risk of bias assessment in included studies}

Table 4 shows the assessment of the risk of bias for the included studies. Thrusfield and others (1998) did not control for the potentially confounding effect of breed, but partially controlled for the effect of age by restriction at the sampling stage, by recruiting dogs born over a period of approximately 3 years. Spain and others (2004) did control for breed but not age. D Bleser and others (2011) controlled for the potential effects of both age and breed. All three included studies had low follow-up and/or response rates, particularly the Thrusfield study (1998) in which only 16 of 233 enlisted veterinarians returned case notes, and of the cases included approximately one-third were not followed for the whole study period. There was further loss of data due to incomplete case notes. These issues can potentially lead to bias if the included data is not representative of the dog population as a whole, e.g. if owners were more likely to report, or veterinarians were more likely to recall, and therefore record, cases in which incontinence occurred after neutering, as opposed to incontinence occurring in entire bitches. In two studies (Thrusfield and others 1998, Spain 2004), it was not clear whether both the presence and absence of urinary incontinence had been reliably classified. Other potential areas of bias are summarised in Table 4. 


\section{Table 2. Studies excluded due to potential bias, showing reasons for exclusion, according to prespeci- \\ fled criteria}

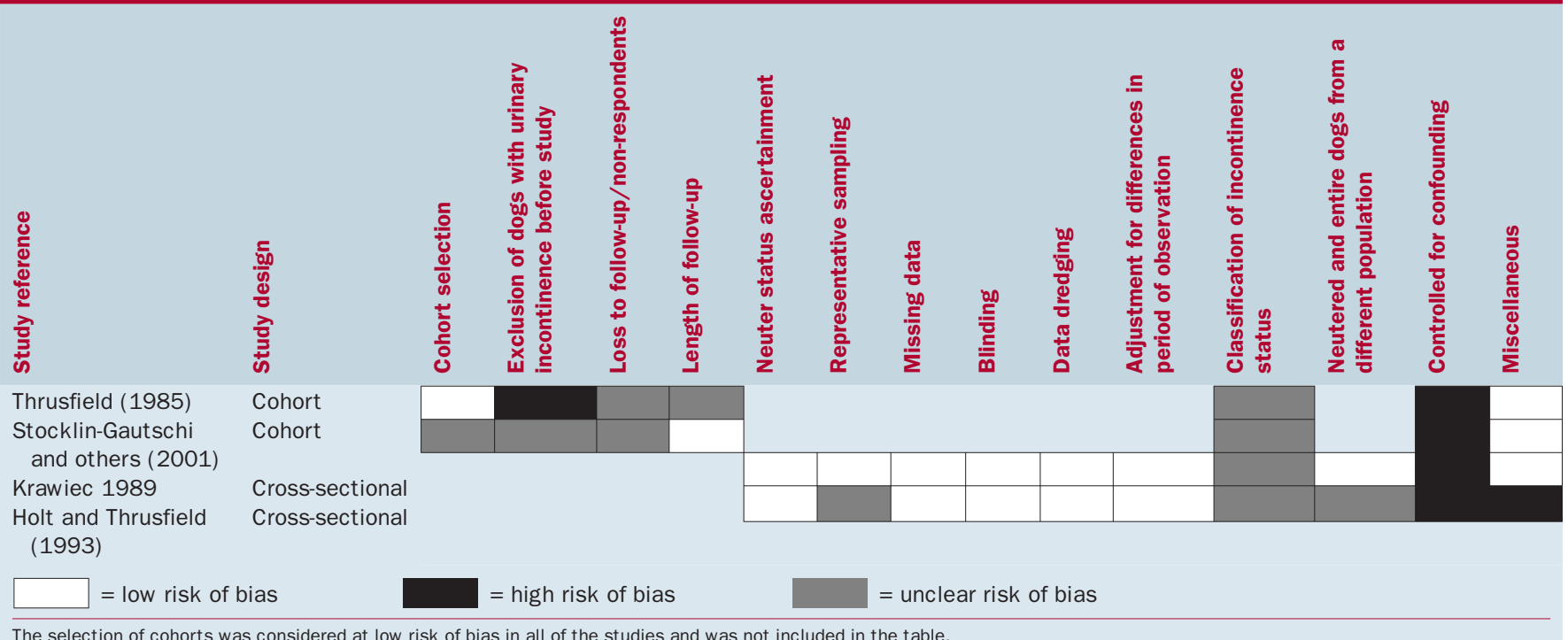

The selection of cohorts was considered at low risk of bias in all of the studies and was not included in the table.

Table 3. Key features of all included studies in a systematic review to address the association between neutering/age of neutering and frequency of urinary incontinence

\begin{tabular}{|c|c|c|c|c|c|c|c|}
\hline Study & Period of observation & Country & Study design & Number of dogs & Study population* & Age of dogs & Age at neutering \\
\hline \multicolumn{8}{|c|}{ Association between neutering $\dagger$ and urinary incontinence $\neq$} \\
\hline $\begin{array}{l}\text { Thrusfield and } \\
\text { others (1998) }\end{array}$ & 1987 to 1992 & UK & Cohort & 504 & Private practice cases & $\begin{array}{l}12 \text { weeks to } \\
5 \text { years }\end{array}$ & 4 to $35^{\S}$ months \\
\hline \multicolumn{8}{|c|}{ Association between age at neutering $\dagger$ and urinary incontinence $\uparrow$} \\
\hline $\begin{array}{l}\text { Thrusfield and } \\
\text { others (1998) }\end{array}$ & 1987 to 1992 & UK & Cohort & 310 & Private practice cases & $\begin{array}{l}13 \text { weeks to } \\
5 \text { years }\end{array}$ & 4 to $35^{\S}$ months \\
\hline $\begin{array}{l}\text { Spain and others } \\
\text { (2004) }\end{array}$ & 1989 to 2001 & USA & Cohort & $983^{\dagger}$ & $\begin{array}{l}\text { Dogs re-homed by a } \\
\text { charity }\end{array}$ & $\begin{array}{l}6 \text { months to } \\
12 \cdot 2^{\dagger} \text { years }\end{array}$ & 1.5 to 12 months \\
\hline $\begin{array}{l}\text { de Bleser and } \\
\text { others (2011) }\end{array}$ & 2005 to 2006 & UK & Case control & $314^{\infty} ; 329^{\#}$ & Private practice cases & $\begin{array}{r}<5 \text { years to } \\
>12 \text { years }\end{array}$ & $<1$ to $>12$ years \\
\hline
\end{tabular}

"All studies included female dogs only

tAll studies used terms such as "gonadectomy," "spay" or "neuter" that were not defined further

"Thrusfield and others (1998) includes "Acquired urinary incontinence" cases (not defined further) only. Spain and others (2004) includes "urinary incontinence" cases (not defined further). de Bleser and others (2011) includes "sphincter mechanism incontinence" cases and explicitly defined cases, for the purposes of the study, as bitches currently receiving treatment for the condition

${ }^{s}$ Cases only

×For analysis of age of neutering

"For analysis of number of seasons before neutering

Table 4. Risk of bias assessment in the included studies.

\begin{tabular}{|c|c|c|c|c|c|c|c|c|}
\hline Study reference & $\begin{array}{l}\text { Study } \\
\text { design }\end{array}$ & $\begin{array}{l}\text { Exclusion } \\
\text { of dogs } \\
\text { with urinary } \\
\text { incontinence } \\
\text { before study }\end{array}$ & $\begin{array}{l}\text { Loss to } \\
\text { follow-up/non- } \\
\text { respondents }\end{array}$ & $\begin{array}{l}\text { Missing data/ } \\
\text { non-respon- } \\
\text { dents }\end{array}$ & $\begin{array}{l}\text { Ascertainment } \\
\text { of age at } \\
\text { neutering }\end{array}$ & $\begin{array}{l}\text { Classification } \\
\text { of inconti- } \\
\text { nence status }\end{array}$ & $\begin{array}{l}\text { Controlled for } \\
\text { confounding }\end{array}$ & Miscellaneous \\
\hline $\begin{array}{l}\text { Thrusfield and } \\
\text { others (1998) }\end{array}$ & Cohort & & & & & & & \\
\hline $\begin{array}{l}\text { Spain and oth- } \\
\text { ers (2004) }\end{array}$ & Cohort & & & & & & & \\
\hline $\begin{array}{l}\text { de Bleser and } \\
\text { others (2011) }\end{array}$ & $\begin{array}{l}\text { Case } \\
\text { control }\end{array}$ & & & & & & & \\
\hline$=$ low ris & $\mathrm{k}$ of bias & & ligh risk of $b$ & & nclear $\mathrm{r}$ & f bias & & \\
\hline
\end{tabular}

White colour denotes low risk of bias, black colour denotes high risk of bias and grey colour indicates unclear risk of bias

The following areas were considered to be at low risk of bias in all of the studies and are not included in the table - case control studies: case definition, case selection, control definition, neuter status ascertainment same for cases and controls; cohort studies: selection of cohorts, ascertainment of neuter status, length of follow-up 


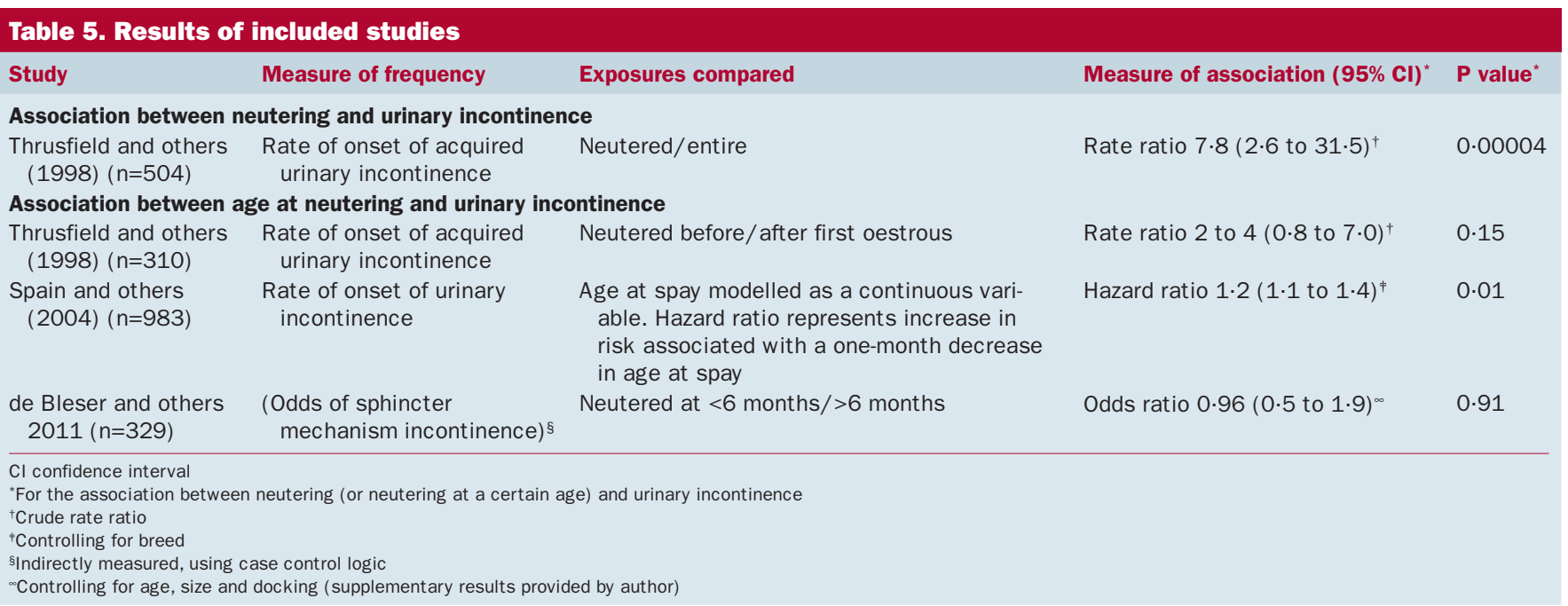

\section{Study results}

The effect of neutering on the risk of urinary incontinence. Only one of the eligible studies compared neutered and entire dogs (Table 5, Thrusfield and others 1998) and found that neutering was associated with an approximate eight-fold increase in rate of urinary incontinence (rate ratio $7 \cdot 8,95 \%$ CI 2.6 to 31.5 , $\mathrm{P}=0.00004)$.

The effect of age at neutering on the risk of urinary incontinence. The two UK studies found no evidence of an association between urinary incontinence and age at spay [de Bleser and others 2011, $\mathrm{P}=0.91$ (supplementary results provided by author); Thrusfield and others $1998, \mathrm{P}=0 \cdot 15]$ and in one of these there was a trend towards a decrease in odds of urinary incontinence with decreased age at spay, although this relationship was not statistically significant (de Bleser and others 2011). However, the study of re-homed dogs in the USA reported a linear relationship between age at spay and rate of urinary incontinence in dogs spayed between 6 weeks and 12 months of age, with each onemonth decrease in age at spay associated with an increased rate of incontinence (hazard ratio $1.2 ; 95 \%$ CI 1.1 to $1.4 ; \mathrm{P}=0.01$ ). This study also reported that the hazard ratio for incontinence was 3.5 for dogs neutered before three months of age versus after three months of age $(\mathrm{P}<0.001)$ (Spain and others 2004). It would be useful to know if the linear model gave the best fit for the data, or not; however, this was not clear in the report.

\section{Strength of evidence assessment}

Evidence for the effect of both neutering and age at neutering on the risk of urinary incontinence was classified as SIGN level D (weakest) (Table 6). For the association between neutering and urinary incontinence, the main reason for this classification was that there was only one included study addressing this issue. In addition, this study was classified as at moderate risk of bias, for the reasons discussed above. For the association between age at neutering and urinary incontinence, although three studies addressed the research question, only one study found an association and again there was a plausible risk of bias within this study, so the evidence could only be classed as weak.

\section{DISCUSSION}

The objectives of this study were to estimate the strength of evidence for effect size, and of any association between neutering or age at neutering and the risk of urinary incontinence. On the basis of the three included studies, which were all judged to be at moderate risk of bias, there is only weak evidence that neutering bitches, particularly before the age of three months, increases the risk of urinary incontinence. This classification of the evidence as weak is based on SIGN guidelines, which require several well-conducted studies with a low risk of bias and confounding, and with overall consistent results, for the overall evidence to be classified as at least $\mathrm{C}$ (on a scale from $\mathrm{A}$ to $\mathrm{D}$ ). On this scale, the strongest level of evidence (A) would only be given if there was a consistent body of well-conducted randomised controlled trials with a low risk of bias (or a meta-analysis providing strong evidence).

Only one included study compared neutered and entire dogs (Thrusfield and others 1998), reporting a strong association between neutering and acquired urinary incontinence [rate ratio $7 \cdot 8,95 \%$ confidence interval (CI) 2.6 to 31.5 ]. However, very low response rates were a potential source of bias in this study. In addition, neither age nor breed was adjusted for in the analysis, although the cohorts were born within a 3-year period so the effect of age as a potential confounder was minimized to some extent.

Two UK studies (de Bleser and others 2011, Thrusfield and others 1998) found no association between urinary incontinence and age at spay. However, a study of re-homed dogs in the USA found a linear relationship between age at spay and rate of urinary incontinence in dogs spayed between 6 weeks and 12 months of age, with each one-month decrease in age at spay associated with an increased rate of incontinence. The different results may be explained in part by differences in age at neutering: in the UK studies, no dogs were neutered before 4.5 months, whereas in the USA study, many were neutered before 4.5 months and some as young as six weeks. The latter study additionally reported an increased risk of incontinence when animals were neutered at less than three months of age, compared with more than three 
Table 6. Summary of findings of a systematic review of the effect of neutering on the risk of urinary incontinence (of any type) in female dogs

\begin{tabular}{|c|c|c|c|}
\hline $\begin{array}{l}\text { Measure of association ( } 95 \% \text { confidence } \\
\text { interval) }\end{array}$ & $\begin{array}{l}\text { Number of dogs } \\
\text { in each study }\end{array}$ & $\begin{array}{l}\text { Grade of recommenda- } \\
\text { tion (on scale A to D) }\end{array}$ & Comments \\
\hline \multicolumn{4}{|c|}{ Association between neutering and urinary incontinence } \\
\hline $\begin{array}{l}\text { Thrusfield and others (1998): rate ratio } 7.8 \\
(2.6 \text { to } 31.5)\end{array}$ & $809^{*}$ & $\mathrm{D}$ & $\begin{array}{l}\text { Did not control for potential confounder: breed; partially } \\
\text { controlled for age by restriction } \\
\text { Unclear if presence/absence of urinary incontinence } \\
\text { was reliably ascertained } \\
\text { Low follow-up rates } \\
\text { Very low response rates }\end{array}$ \\
\hline \multicolumn{4}{|c|}{ Association between age at neutering and urinary incontinence } \\
\hline $\begin{array}{l}\text { Thrusfield and others }(1998) \text { : rate ratio } \\
\text { (comparing spaying before and after first } \\
\text { oestrous) } 2.4(0.8 \text { to } 7 \cdot 0)\end{array}$ & $346^{*}$ & & See previous comments \\
\hline $\begin{array}{l}\text { Spain and others (2004): hazard ratio } \\
\text { (modelling age at spay as a continu- } \\
\text { ous variable - the value represents the } \\
\text { decrease in risk associated with one- } \\
\text { month decrease in age at spay): } 1 \cdot 2(1 \cdot 1 \\
\text { to } 1 \cdot 4)\end{array}$ & $983^{\dagger}$ & $\mathrm{D}$ & $\begin{array}{l}\text { Unclear if presence/absence of urinary incontinence } \\
\text { was reliably ascertained } \\
\text { It was not established that the dogs were continent } \\
\text { before the start of the study } \\
\text { Short follow-up period } \\
\text { Low follow-up rates }\end{array}$ \\
\hline \multicolumn{4}{|l|}{$\begin{array}{l}\text { Spain and others (2004): hazard ratio } \\
\text { (comparing spaying before and after three } \\
\text { months of age): } 3 \cdot 5^{\dagger}\end{array}$} \\
\hline $\begin{array}{l}\text { de Bleser and others (2011): odds ratio } \\
\text { (comparing spaying before and after six } \\
\text { months of age) } 0.96(0.5 \text { to } 1.9)\end{array}$ & $329^{\S}$ & & $\begin{array}{l}\text { Low response rate (unlikely to cause under-estimation } \\
\text { of effect) } \\
\text { Possible non-differential misclassification of age at spay }\end{array}$ \\
\hline
\end{tabular}

months (hazard ratio 3.5; $\mathrm{P}<0.001$ ) (Spain and others 2004), although it was unclear why this cut-off was chosen. There were, however, potential sources of bias in all of these studies. In particular, in the USA study, the presence/absence of urinary incontinence was assessed by questionnaire and no precise definition of urinary incontinence was given.

In summary, there is some evidence that neutering is associated with an increased risk of urinary incontinence, and that the earlier a bitch is neutered, the greater the associated risk. However, the studies that only included dogs spayed at 4.5 months of age or older did not find any association between age at neutering and risk of urinary incontinence. One possible explanation for this is that there is a stronger association between neutering and incontinence in dogs neutered between 6 weeks and 4.5 months of age, but as already discussed other explanations may include bias, differences in power or study populations.

No study found an association between urinary incontinence and occurrence of oestrous before spay. In addition, the only study that found an association between age at spay and risk of incontinence, found a linear association (Spain and others 2004), which appears to support the fact that oestrous itself does not play a functional role in the aetiology. However, much more detailed analysis of the results would be necessary to confirm this, especially because age at oestrous varies across different breeds. This contrasts with a body of evidence, which suggests that ovarian steroids do affect the urethral sphincter mechanism (Byron and others 2007, Holt 1990).

These issues combined with the heterogeneity amongst studies contributed to the overall strength of evidence for each outcome being assigned a level of $\mathrm{D}$ (weakest).

\section{Study limitations}

One limitation of this study was that, due to practical constraints, only published, peer-reviewed English articles could be included. Including only published, peer-reviewed papers may make the results susceptible to publication bias (Dohoo and others 2010). However, it is not certain that bias is reduced by extensive searching for unpublished observational studies. It has even been suggested that this could increase bias because of the large number of poor quality observational studies in unpublished literature (Higgins and Green 2009).

Owing to heterogeneity in study outcomes, units of measurement, study design, study population, control of confounding and potential bias, generation of summary effect measures was not feasible and individual results have been reported.

Out of seven potentially eligible studies, we found that four were at high risk of bias, according to our criteria, and the remainder were judged to be at moderate risk of bias. Future studies should take into account the potential confounders age and breed. In addition, tail docking should be considered as a potential confounder, as it 
has been found to be associated with urinary incontinence (Holt and Thrusfield 1993, de Bleser and others 2011), although this may be because of its close relationship with breed. Future studies of the effect of age at neutering on urinary incontinence may require either a large range of ages at neutering or large numbers of dogs to be sufficiently powered to detect a biologically relevant magnitude of effect at a 95\% statistically significant level.

A number of other factors, which were beyond the scope of this review, need to be considered when deciding whether, and when, to neuter dogs, e.g. the prevalence and welfare implications of urinary incontinence, as well as the strength of evidence, prevalence and welfare implications for other conditions potentially associated with neutering.

The decision-making process may be even more complex when the broad range of effects on the owner, or other pets in the household, (e.g. aggression, the inconvenience and economic cost of conditions or their treatment) or effects on the wider population of people and animals (aggressiveness, unwanted animals and strays) are taken into account.

\section{Conclusion}

The evidence for a causal relationship between neutering and urinary incontinence is weak, although there is some evidence of an association. There is some weak evidence that the risk of urinary incontinence decreases as the age at spay increases, up to 12 months of age, after which there is no evidence of an effect of age at spay. There was no direct evidence found in this review that the occurrence or absence of oestrous before neutering plays a role in the aetiology of urinary incontinence. This information should be balanced with other available information on the risks and benefits of neutering.

Further research on the association between urinary incontinence and neutering should focus on recording age, breed and tail docking as potential confounders. Occurrence of oestrous before neutering should be recorded and studies should ideally include dogs neutered at a wide range of ages. In addition, a reliable definition of urinary incontinence should be used, and it should be shown that dogs considered to be continent do not in fact meet this case definition.

\section{Acknowledgements}

We would like to thank Dogs Trust for funding this work, staff at the Royal Veterinary College Library and British Library for assistance and advice in locating articles and Jennifer Summers for advice on the methods.

\section{Conflict of interest}

None of the authors of this article has a financial or personal relationship with other people or organisations that could inappropriately influence or bias the content of the paper.

\section{References}

CAB DIRECT. (2011) http://www.cabdirect.org. Accessed June 10, 2011

Brron, J. K., March, P. A., Chew, D. J. \& DiBartola, S. P. (2007) Effect of phenylpropanolamine and pseudoephedrine on the urethral pressure profile and continence scores of incontinent female dogs. Journal of Veterinary Internal Medicine 21, 47-53

de Bleser, B., Brodbelt, D. C., Gregory, N. G. \& Martinez, T. A. (2011) The association between acquired urinary sphincter mechanism incompetence in bitches and early spaying: a case-control study. Veterinary Journal 187, 42-47

Diesel, G., Brodbelt, D. \& Laurence, C. (2010) Survey of veterinary practice policies and opinions on neutering dogs. Veterinary Record 166, 455-458

Dohoo, I., MARTIN, W. \& StryHn, H. (2010) Veterinary Epidemiologic Research VER Inc., Charlotte Town, Prince Edward Island, Canada

Downs, S. H. \& Black, N. (1998) The feasibility of creating a checklist for the assessment of the methodological quality both of randomised and non-randomised studies of health care interventions. Journal of Epidemiology and Community Health 52, 377-384

Galav, V. A. \& Singh, A. P. (2004) Urinary incontinence in bitches: principal causes and treatment. Veterinary Practitioner 5, 147-149

Gregory, S. P., Parkinson, T. J. \& Holt, P. E. (1992) Urethral conformation and position in relation to urinary incontinence in the bitch. Veterinary Record 131, 167-170

HigGins, J. P. T. \& Green, G. Cochrane handbook for systematic reviews of interventions, version 5.0.2 [updated september 2009]

HoLt, P. E. (1987) Urinary incontinence in the dog and cat. Tijdschr Diergeneeskd 112(Suppl 1), 92S-97S

HoLt, P. E. (1990) Urinary incontinence in dogs and cats. Veterinary Record 127, 347-350

Holt, P. E. \& Thrusfield, M. V. (1993) Association in bitches between breed, size, neutering and docking, and acquired urinary incontinence due to incompetence of the urethral sphincter mechanism. Veterinary Record 133, $177-180$

HowE, L. M. (2006) Surgical methods of contraception and sterilization. Theriogenology 66, 500-509

Howe, L. M., Slater, M. R., Boothe, H. W., Hobson, H. P., Holcom, J. L. \& Spann, A. C. (2001) Long-term outcome of gonadectomy performed at an early age or traditional age in dogs. Journal of the American Veterinary Medical Association 218, 217-221

ISI WeB OF KNowledge. (2011) http://wok.mimas.ac.uk/. Accessed June 10, 2011

Jagoe, J. A. \& Serpell, J. A. (1988) Optimum time for neutering. Veterinary Record 122, 447

KRAWIEC, D. R. (1989) Diagnosis and treatment of acquired canine urinary incontinence. Companion animal practise 19, 12-20

Kustritz, M. V. (2002) Early spay-neuter: clinical considerations. Clinical Techniques in Small Animal Practice 17, 124-128

Kustritz, M. V. R. (2007) Determining the optimal age for gonadectomy of dogs and cats. Journal of the American Veterinary Medical Association 231, 1665-1675

Liberati, A., Altman, D. G., Tetzlaff, J., Mulrow, C., Gotzsche, P. C., Ioannidis, J. P., Clarke, M., Devereaux, P. J., Kleijnen, J. \& Moher, D. (2009) The PRisma statement for reporting systematic reviews and meta-analyses of studies that evaluate health care interventions: explanation and elaboration. Journal of Clinical Epidemiology 62, e1-e34

Mandigers, P. J., Senders, T. \& Rothuizen, J. (2006) Morbidity and mortality in 928 Dobermanns born in the Netherlands between 1993 and 1999. Veterinary Record 158, 226-229

NoËL, S., Claeys, S. \& Hamaide, A. (2010) Acquired urinary incontinence in the bitch: update and perspectives from human medicine. Part 2: the urethral component, pathophysiology and medical treatment. The Veterinary Journal 186, $18-24$

O'Nualáín, N. (1987) Some aspects of canine and feline reproduction. Veterinary Update 1, 1-2

Ottawa Hospital Research Institute. (2011) http://www.ohri.ca/programs/clinical epidemiology/oxford.asp. Accessed June 10, 2011

PhILliPs, T. (1992) Pros and cons. Early neutering. Pet Veterinarian 4, 4-5

Scottish Intercollegiate Guidelines Network. (2008) http://www.sign.ac.uk/guidelines/fulltext/50/index.html. Accessed, 10 June 2011

Shiel, R. E., Puggioni, A. \& Keeley, B. J. (2008) Canine urinary incontinence. Part 2: treatment. Irish Veterinary Journal 61, 835-840

Spain, C. V., ScArlett, J. M. \& Houpt, K. A. (2004) Long-term risks and benefits of early-age gonadectomy in dogs. Journal of the American Veterinary Medical Association 224, 380-387

Stocklin-Gautschi, N. M., Hassig, M., Reichler, I. M., Hubler, M. \& Arnold, S. (2001) The relationship of urinary incontinence to early spaying in bitches. Journal of Reproduction and Fertility Supplement 57, 233-236

THRUSFIELD, M. V. (1985) Association between urinary incontinence and spaying in bitches. Veterinary record 116, 695

Thrusfield, M. V., Holt, P. E. \& Muirhead, R. H. (1998) Acquired urinary incontinence in bitches: its incidences and relationship to neutering practices. Journal of Small Animal Practice 39, 559-566

UNIVERSITY OF LIVERPOOL. (2011) http://www.liv.ac.uk/dog-aggression/Level_of_ evidence.htm. Accessed June 10, 2011

U.S. National Library of Medicine. (2011) http://www.ncbi.nlm.nih.gov/pubmed. Accessed June 10, 2011 